\title{
Caracterização morfológica do agregado leve de argila expandida brasileira com utilização do AIMS
}

\author{
Morphological characterisation of Brazilian expanded clay \\ lightweight aggregate using AIMS
}

\section{Júlio Jorge Braga de Carvalho Nunes \\ Ana Maria Abreu Jorge Teixeira \\ Rebeca Montenegro Dias de Carvalho Saraiva}

\section{Resumo \\ D}

evido ao formato excessivamente arredondado da argila expandida (AE), dados relativos à angularidade, à esfericidade e à textura superficial podem auxiliar no entendimento da relação desses fatores com as propriedades do concreto no estado fresco, como

trabalhabilidade e fluidez. Esta pesquisa buscou caracterizar a $\mathrm{AE}$ quanto à morfologia e compará-la com as particularidades do agregado convencional por meio da utilização do equipamento Aggregate Imaging Measurement System (AIMS). Os resultados indicam que a caracterização morfológica dos agregados graúdos convencionais (brita 0 e brita 1 ) apresentam angularidade subarredondada e esfericidade moderada em ambas as partículas, já a textura superficial é rugosa e áspera, respectivamente para a brita 0 e brita 1 . Para os agregados graúdos de $\mathrm{AE}$ brasileira AE 2215 e AE 1506, as características morfológicas como a angularidade e a textura superficial foram definidas como arredondadas e polidas, respectivamente, em ambos os grupos. No entanto, houve diferenciação quanto à esfericidade, que é alta para a AE 2215 e moderada para a AE 1506.

Comparativamente ao grupo de agregados convencionais, o agregado leve graúdo de AE brasileira indica partículas mais arredondadas, com média-alta esfericidade e textura superficial mais lisa.

Palavras-chave: Argila expandida. Agregado leve. Angularidade. Esfericidade. Textura superficial.

1Júlio Jorge Braga de Carvalho Nunes

IInstituto Militar de Engenharia Rio de Janeiro - RJ - Brasil

${ }^{2}$ Ana Maria Abreu Jorge Teixeira Instituto Militar de Engenharia Rio de Janeiro - RJ - Brasil

${ }^{3}$ Rebeca Montenegro Dias de Carvalho Saraiva ${ }^{3}$ Instituto Militar de Engenharia Rio de Janeiro - RJ - Brasil

Recebido em 22/05/20 Aceito em 28/08/20

\section{Abstract}

Due to the excessively rounded shape of expanded clay, data related to angularity, sphericity and surface texture can help to understand the relationship of these factors with the properties of concrete in the fresh state, such as workability and fluidity. This research sought to characterize the expanded clay in terms of morphology and to compare it with the particularities of the conventional aggregate using the AIMS (Aggregate Imaging Measurement System) equipment. The results indicate that the morphological characterization of conventional coarse aggregates (BO and $B 1)$ are presented with subrounded angulation and moderate sphericity in both particles, whereas the surface texture is rough and harsh, respectively for $B O$ and B1. For coarse aggregates of Brazilian AE 2215 and $A E$ 1506, the morphological characteristics such as angularity and surface texture were defined as rounded and polished, respectively, in both groups. However, there was differentiation as to sphericity, which is high for $A E 2215$ and moderate for $A E$ 1506. Compared to the group of conventional aggregates, the lightweight coarse aggregate of Brazilian expanded clay indicates more rounded particles, with medium-high sphericity and surface texture smoother.

Keywords: Expanded clay. Lightweight aggregate. Angularity. Sphericity. Surface texture. 


\section{Introdução}

\section{Aggregate Imaging Measurement System - AIMS}

O equipamento denominado Aggregate Imaging Measurement System (em português, sistema de medição de imagem dos agregados [AIMS]), desenvolvido pelo Texas Department of Transportation e pela Federal Highway Administrations (FHWA), utiliza recursos de microscopia e de análise da captura de imagens do agregado para definir características morfológicas como angularidade, esfericidade e textura superficial. Segundo a FHWA, as características morfológicas dos agregados influenciam no desempenho estrutural e na resistência de estruturas. Sua classificação precisa é essencial para o entendimento da relação entre o agregado e a matriz da mistura que o envolve.

A ferramenta do AIMS é utilizada para avaliar a forma dos agregados e suas propriedades, utilizando imagens digitais nas quais a tecnologia tem o potencial de melhorar a qualidade e a segurança dos dados obtidos. Há métodos utilizados atualmente para determinar as características e as formas dos agregados que influenciam o desempenho estrutural de projetos de pavimentação ou concreto, que são subjetivos e que consomem muito tempo, como a determinação do Índice de Forma pelo método do paquímetro, segundo a norma NBR 7809 (ABNT, 2008). O AIMS se apresenta como um equipamento eficiente que avalia o design da imagem do agregado e utiliza um sistema de microscópio-câmera de ampliação variável e duas configurações de iluminação para capturar as imagens a serem analisadas pelo software, com a capacidade de quantificar objetivamente as formas nas escalas macro e micro.

A Figura 1 mostra a parte interna do AIMS da Universidade Federal do Rio de Janeiro (UFRJ) e um exemplo de equipamento AIMS.

A caracterização morfológica dos agregados pode auxiliar no estudo do comportamento dos materiais na construção civil - por exemplo, na aplicação do concreto, onde os dados relativos à angularidade, à esfericidade e ao formato $2 \mathrm{D}$ da $\mathrm{AE}$ podem influenciar significativamente nas propriedades do concreto no estado fresco, como trabalhabilidade e fluidez, mas podem prejudicar a homogeneidade do material, formando ninhos de segregação, o que pode ser notado também nos estudos do Comité Euro-Internacional du Béton e Fédération Internationale de la Précontrainte (COMITE..., 1977).

Castelo Branco et al. (2006) afirmam que o AIMS se caracteriza como um sistema digital interligado a um hardware de aquisição de imagens e a um computador, que recebe os dados do sistema para, em seguida, analisá-los, tornando possível determinar algumas características físicas como a forma, a angularidade, a esfericidade e a textura superficial de agregados graúdos e miúdos.

Bessa (2012) observou que a utilização do AIMS na caracterização de agregados é importante para obter uma análise mais completa e detalhada dos parâmetros da forma, da esfericidade, da angularidade e da textura superficial, recebendo não só uma média de valores, mas também distribuições de propriedades. No caso do agregado leve de AE, essa avaliação pode contribuir para uma melhor análise de como a angularidade e a esfericidade podem interferir em fatores como trabalhabilidade e fluidez em concretos, além de avaliar como a textura superficial influencia na aderência e na iteração entre o agregado e a matriz de cimento na zona de transição.

Figura 1 - (a) Parte interna do AIMS da UFRJ; e (b) Equipamento AIMS do fabricante PINE Instrument.

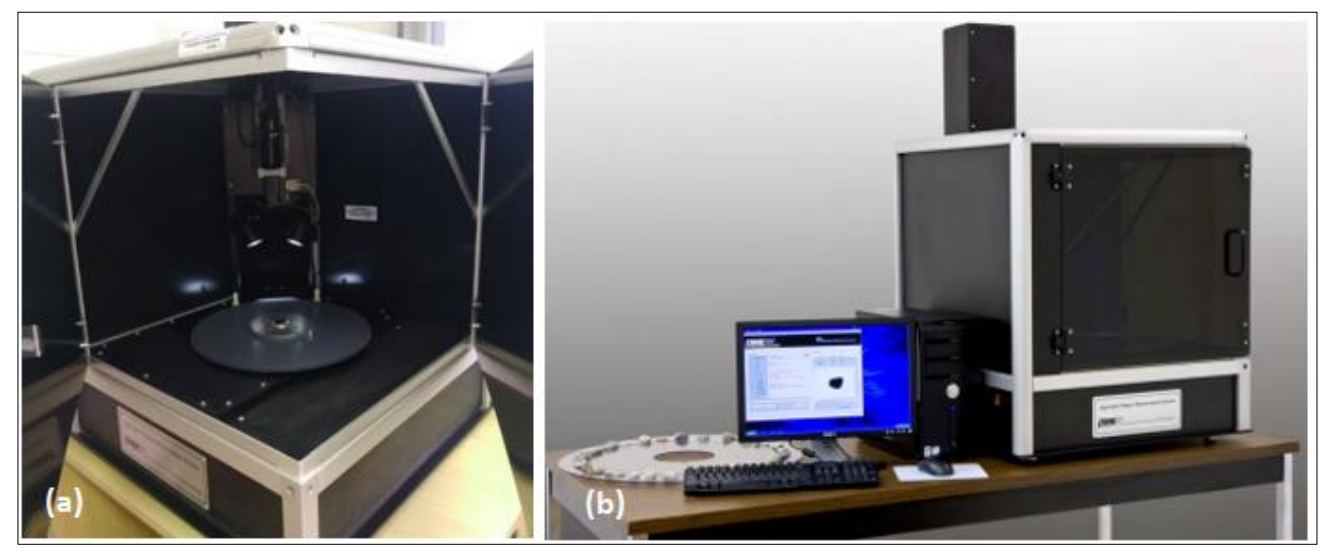

Fonte: (b) Gates et al. (2011).

214 Nunes, J. J. B. de C.; Teixeira, A. M. A. J.; Saraiva, R. M. D. de C. 
Santana (2017) e Azevedo (2017) utilizaram o AIMS para classificar a brita 0 quanto às características morfológicas das partículas, fornecendo dados referentes à angularidade, à textura, ao índice de forma e à esfericidade, visando sua aplicação em concreto projetado com fibras de poliolefina para túneis e para a utilização do concreto para vigas pultrudadas preenchidas para dormentes ferroviários, respectivamente.

\section{Argila expandida brasileira}

A AE brasileira é um agregado leve produzido no Estado de São Paulo, na região de Várzea Paulista, no Estado de São Paulo. Já deve informar o fabricante que é um material com propriedade de isolante térmico e é constituído por uma crosta microporosa rígida e de alta resistência, com o interior formado por uma massa cerâmica porosa. O processo de fabricação é realizado em forno rotativo a uma temperatura de $1.200{ }^{\circ} \mathrm{C}$, e a comercialização é feita em sacos de $50 \mathrm{~L}$ ou a granel. É um produto natural e apresenta como principais propriedades ser um material incombustível de baixa densidade, alta porosidade e que não se degrada com o tempo (CINEXPAN, 2000).

De acordo com o fabricante, a AE em sua forma original (solta e sem outros aditivos) pode ser utilizada na construção civil (para enchimentos leves em diversas etapas da obra, na formação de concreto leve e em nata de cimento) ou na troca do solo (geotecnia). Os tipos mais comuns de AE são a AE 0500 (com diâmetro das partículas até $5 \mathrm{~mm}$ e utilizado normalmente em concreto leve e enchimento até $5 \mathrm{~cm}$ ), a AE 1506 (com diâmetro das partículas entre 6 e $15 \mathrm{~mm}$, também utilizado em concreto leve e enchimento até $5 \mathrm{~cm}$ ) e a $\mathrm{AE}$ 2215 (com diâmetro das partículas até entre 15 e $22 \mathrm{~mm}$, utilizado em enchimento de vazios, isolamento térmico e paisagismo).

Na Tabela 1 são apresentados os dados da composição química e das propriedades físicas e mecânicas do fabricante para os três tipos de AE avaliados nesta pesquisa.

Cabe destacar que as propriedades químicas permanecem as mesmas, pois se trata do mesmo material, conservando-se também o processo de fabricação. Por sua vez, a densidade aparente e a massa específica são bastante distintas entre as classes de $\mathrm{AE}$, pois a variação da dimensão do grão implica em diferentes índices e vazios no interior dos grãos. Já a condutividade térmica e o isolamento acústico apresentam comportamento semelhantes para as diferentes classes citadas. Por fim, com relação à resistência ao esmagamento, verifica-se que quanto menor é o grão, maior é a resistência obtida.

Tabela 1 - Dados da composição química e das propriedades físicas e mecânicas do fabricante

\begin{tabular}{|c|c|c|c|}
\hline \multicolumn{4}{|c|}{ COMPOSIÇÃO QUÍMICA } \\
\hline Composição/ tipo de AE & AE 2215 & AE1506 & AE0500 \\
\hline Silício $\left(\mathrm{em} \mathrm{SiO}_{2}\right)$ & \multicolumn{3}{|c|}{$63,19 \%$} \\
\hline Alumínio $\left(\mathrm{em} \mathrm{Al}_{2} \mathrm{O}_{3}\right)$ & \multicolumn{3}{|c|}{$18,02 \%$} \\
\hline Ferro $\left(\mathrm{em} \mathrm{Fe}_{2} \mathrm{O}_{3}\right)$ & \multicolumn{3}{|c|}{$7,63 \%$} \\
\hline Titânio $\left(\mathrm{em} \mathrm{TiO}_{2}\right)$ & \multicolumn{3}{|c|}{$0,92 \%$} \\
\hline Cálcio (em CaO) & \multicolumn{3}{|c|}{$0,64 \%$} \\
\hline Magnésio (em MgO) & \multicolumn{3}{|c|}{$3,26 \%$} \\
\hline Sódio $\left(\mathrm{em} \mathrm{Na}_{2} \mathrm{O}\right)$ & \multicolumn{3}{|c|}{$0,61 \%$} \\
\hline Potássio $\left(\mathrm{em} \mathrm{K}_{2} \mathrm{O}\right)$ & \multicolumn{3}{|c|}{$4,91 \%$} \\
\hline Óxido de Fósforo (em $\left.\mathrm{P}_{2} \mathrm{O}_{5}\right)$ & \multicolumn{3}{|c|}{$0,20 \%$} \\
\hline Óxido de Manganês (em MnO) & \multicolumn{3}{|c|}{$0,08 \%$} \\
\hline Óxido de Bário (em $\mathrm{BaO})$ & \multicolumn{3}{|c|}{$0,09 \%$} \\
\hline \multicolumn{4}{|c|}{ PROPRIEDADES FÍSICAS E MECÂNICAS } \\
\hline Propriedades/tipo de AE & AE 2215 & AE1506 & AE0500 \\
\hline Densidade aparente $(\mathrm{kg} / \mathrm{m})$ & $500 \pm 10 \%$ & $600 \pm 10 \%$ & $850 \pm 10 \%$ \\
\hline Massa específica $(\mathrm{kg} / \mathrm{m})$ & 640,00 & $1.110,00$ & $1.560,00$ \\
\hline Classes granulométricas (mm) & $15-22$ & $06-15$ & $0-5$ \\
\hline Resistência mecânica (MPa) & 1,80 & \multicolumn{2}{|c|}{2,30} \\
\hline Condutividade térmica $(\mathrm{W} /(\mathrm{m} . \mathrm{K}))$ & \multicolumn{3}{|c|}{$0,10-0,16$} \\
\hline Isolamento acústico médio (dB) & \multicolumn{3}{|c|}{44,00} \\
\hline
\end{tabular}

Fonte: CINEXPAN (2000). 


\section{Influência da característica morfológica dos agregados nos concretos}

Os agregados leves utilizados na produção do concreto de baixa densidade podem ser naturais ou artificiais. Os agregados leves naturais são obtidos a partir da extração em jazidas, tendo pouca aplicação em concretos estruturais devido à variação de suas propriedades e à pouca disponibilidade. Os agregados leves artificiais, por sua vez, são produzidos por meio de processos industriais (MAYCÁ; RECENA; CREMONINI, 2008). Entre os materiais artificiais, estão os resultantes da aplicação de calor, como no processo de expansão de argilas (MORAVIA et al., 2004). Por serem produzidas em fornos rotativos, as argilas expandidas apresentam formatos excessivamente arredondados e superfícies polidas.

Segundo Gopi et al. (2015), o uso de AE como agregado em concretos leves autoadensáveis (CLA), aliado a adições minerais - principalmente sílica ativa -, pode resultar em um concreto altamente viável e durável. Porém, é preciso atentar para a perda de capacidade de trabalho associada à alta absorção de água (acima de $10 \%$ ) e ao formato arredondado pelos agregados leves, influenciando diretamente nas propriedades do CLA, principalmente no estado fresco.

Considerando as propriedades mecânicas das argilas expandidas, os efeitos da adição desse material em concretos influenciam diretamente em sua composição final, bem como no comportamento da mistura fabricada. $\mathrm{O}$ concreto com agregados leves de $\mathrm{AE}$ apresenta menor resistência à compressão quando comparado ao concreto convencional para a mesma proporção de mistura. Este comportamento pode ser explicado pela menor resistência da AE (ver Tabela 1) quando comparada à do agregado convencional (MORAVIA; GUMIERI; VASCONCELOS, 2010).

A Figura 2 mostra a comparação entre a resistência à compressão do concreto convencional e do concreto leve para a mesma proporção de mistura.

No entanto, do ponto de vista de densidade (em torno de $1.650 \mathrm{~kg} / \mathrm{m}$ ) e de resistência à compressão, os concretos leves analisados neste estudo podem ser classificados como concreto leve estrutural segundo a ACI 213R-14 (AMERICAN..., 2014), que define o concreto leve estrutural como aquele que, aos 28 dias, atinge uma resistência à compressão mínima de $17 \mathrm{MPa}$ e que tem uma massa específica compreendida entre $1.120 \mathrm{~kg} / \mathrm{m}$ e $1.920 \mathrm{~kg} / \mathrm{m}$.

Santana (2017) afirma que a baixa esfericidade dos agregados pode acarretar dificuldades quanto à trabalhabilidade do concreto fresco, dificultando também sua mobilidade e fluidez, por exemplo, em concretos projetados ao longo do interior do mangote de projeção. Já a textura superficial pode facilitar a aderência com a pasta de cimento, trazendo coesão à mistura e formando um compósito mais resistente quando no estado endurecido.

Figura 2 - Resistência à compressão do concreto convencional e do concreto leve para a mesma proporção de mistura

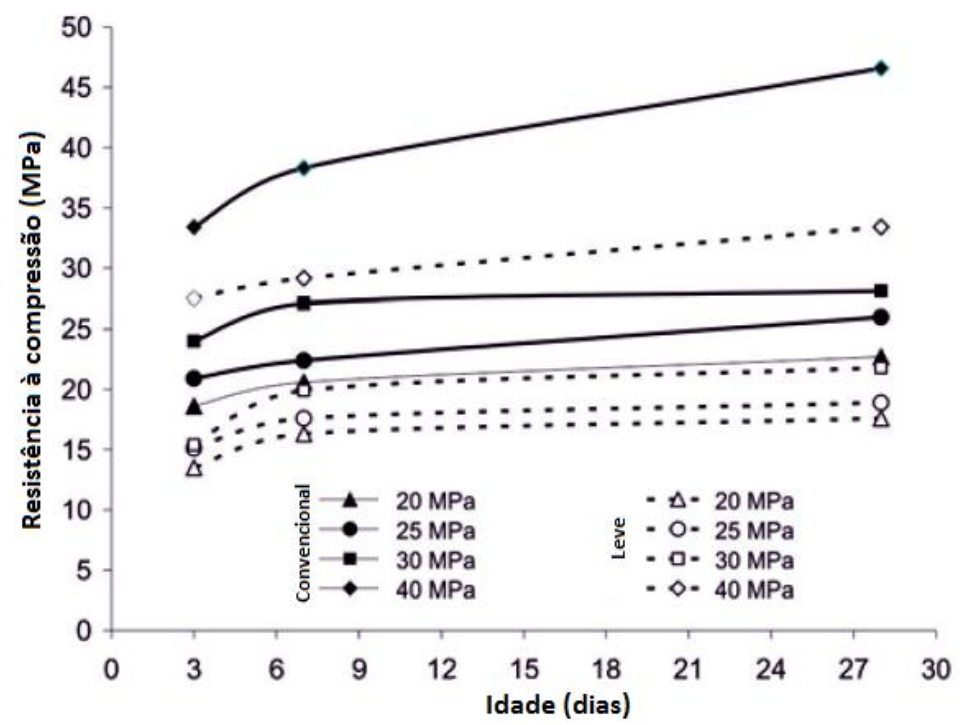

Fonte: adaptado de Moravia, Gumieri e Vasconcelos (2010).

216 Nunes, J. J. B. de C.; Teixeira, A. M. A. J.; Saraiva, R. M. D. de C. 
Dessa forma, a caracterização da morfologia desse agregado pode subsidiar a análise de como a angularidade, a esfericidade e a textura superficial auxiliam no entendimento da relação desses fatores com as propriedades do concreto no estado fresco, como trabalhabilidade e fluidez, e no estado endurecido, como resistência à compressão ou módulo de elasticidade.

\section{Materiais e método}

Foram realizados ensaios não destrutivos de caracterização física e morfológica em agregados graúdos convencionais de brita da região do Rio de Janeiro, bem como em agregados graúdos e miúdos leves de AE brasileira da região de Várzea Paulista.

Quanto à caracterização física, foram realizados ensaios de massa específica seca solta, absorção de água, teor de umidade e teor de material pulverulento, além da análise da curva granulométrica e da definição do diâmetro máximo característico e do módulo de finura. Quanto aos aspectos e à morfologia, foram avaliados dados relativos à angularidade, esfericidade, formato 2D e textura superficial dos agregados.

O programa experimental buscou caracterizar morfologicamente a AE brasileira quanto a aspectos de forma, angularidade, esfericidade e textura superficial. Para tanto, utilizaram-se três tipos de agregados leves mais comumente empregados em concretos leves estruturais: amostras de agregados leves graúdos, representados pelas AE 2215 e AE 1506, e amostras de agregados leves miúdos, representados pela AE 0500. Os materiais foram ensaiados no equipamento AIMS a partir de amostras de brita 0 e brita 1 para efeito de comparação entre os agregados graúdos leves e convencionais, com análise da textura superficial e possível influência na aderência da interface dos agregados graúdos e a pasta de cimento.

\section{Materiais}

\section{Agregado miúdo de argila expandida}

Utilizou-se AE 0500 (com diâmetro variando entre 0 e 5mm) para a composição do agregado miúdo. A Tabela 2 apresenta os resultados dos ensaios físicos de caracterização de agregado miúdo realizados no laboratório.

\section{Agregado graúdo de argila expandida}

Foram utilizadas duas classes de agregados graúdos leves de AE, a AE 2215 (com diâmetro variando entre 15 e $22 \mathrm{~mm}$ ) retida na peneira 12,5mm e a AE 1506 (com diâmetro variando entre 6 e 15mm) retida na peneira 9,5mm. A caracterização desse material está apresentada na Tabela 3.

Tabela 2 - Dados das características da AE 0500 analisada na pesquisa

\begin{tabular}{c|c|c|c}
\hline $\begin{array}{c}\text { Abertura das } \\
\text { peneiras (mm) }\end{array}$ & $\begin{array}{c}\text { Massa retida } \\
\text { média (\%) }\end{array}$ & $\begin{array}{c}\text { Massa acumulada } \\
\text { média (\%) }\end{array}$ & Norma \\
\hline 6,3 & $0,10 \%$ & $0,10 \%$ & \\
4,75 & $4,30 \%$ & $4,40 \%$ & \\
2,36 & $17,10 \%$ & $21,50 \%$ & \\
1,68 & $22,60 \%$ & $44,10 \%$ & \\
0,6 & $43,90 \%$ & $88,00 \%$ & NBR NM 248 (ABNT, 2003a) \\
0,3 & $11,20 \%$ & $99,20 \%$ & \\
0,15 & $0,80 \%$ & $99,90 \%$ & \\
Fundo & $0,10 \%$ & $100,0 \%$ & \\
\hline \multicolumn{2}{c|}{ Módulo de finura (-) } & 3,57 & NBR NM 52 (ABNT, 2009a) \\
Diâmetro máximo (mm) & 4,80 & NBR 9775 (ABNT, 201 1a) \\
Massa específica seca solta (kg/m ) & 880,00 & NBR NM 46 (ABNT, 2003b) \\
\hline \multicolumn{2}{c}{ Teor de umidade (\%) } \\
\multicolumn{2}{c}{ Teor de material pulverulento (\%) } & 10,37 & \\
\hline
\end{tabular}


Tabela 3 - Dados da curva granulométrica e caracterização da AE 1506 e da AE 2215

\begin{tabular}{|c|c|c|c|c|c|}
\hline \multirow[b]{2}{*}{$\begin{array}{c}\text { Abertura das peneiras } \\
(\mathbf{m m})\end{array}$} & \multicolumn{2}{|c|}{ AE 1506} & \multicolumn{2}{|c|}{ AE 2215} & \multirow[b]{2}{*}{ Norma } \\
\hline & $\begin{array}{c}\text { Massa } \\
\text { retida } \\
\text { média }(\%)\end{array}$ & $\begin{array}{c}\text { Massa } \\
\text { acumulada } \\
\text { média }(\%)\end{array}$ & $\begin{array}{c}\text { Massa } \\
\text { retida } \\
\text { média }(\%)\end{array}$ & $\begin{array}{c}\text { Massa } \\
\text { acumulada } \\
\text { média }(\%)\end{array}$ & \\
\hline 38 & $0,00 \%$ & $0,00 \%$ & $0,00 \%$ & $0,00 \%$ & \multirow{11}{*}{ NBR NM 248:2003 } \\
\hline 25 & $0,00 \%$ & $0,00 \%$ & $0,00 \%$ & $0,00 \%$ & \\
\hline 19 & $0,00 \%$ & $0,00 \%$ & $1,35 \%$ & $1,35 \%$ & \\
\hline 12,5 & $17,40 \%$ & $17,40 \%$ & $97,49 \%$ & $98,84 \%$ & \\
\hline 9,5 & $47,68 \%$ & $65,09 \%$ & $0,77 \%$ & $99,61 \%$ & \\
\hline 6,3 & $27,09 \%$ & $92,18 \%$ & $0,05 \%$ & $99,66 \%$ & \\
\hline 4,75 & $6,79 \%$ & $98,18 \%$ & $0,00 \%$ & $99,66 \%$ & \\
\hline 2,36 & $0,39 \%$ & $99,36 \%$ & $0,00 \%$ & $99,66 \%$ & \\
\hline Fundo & $0,64 \%$ & $100,00 \%$ & $0,34 \%$ & $100,00 \%$ & \\
\hline Módulo de Finura (-) & \multirow{2}{*}{\multicolumn{2}{|c|}{$\begin{array}{c}2,63 \\
12,50\end{array}$}} & \multirow{2}{*}{\multicolumn{2}{|c|}{$\begin{array}{c}3,00 \\
19,00\end{array}$}} & \\
\hline Diâmetro máximo (mm) & & & & & \\
\hline $\begin{array}{l}\text { Massa específica seca } \\
\text { solta }(\mathrm{kg} / \mathrm{m})\end{array}$ & \multirow{2}{*}{\multicolumn{2}{|c|}{$\begin{array}{c}499,00 \\
12,75\end{array}$}} & \multirow{2}{*}{\multicolumn{2}{|c|}{$\begin{array}{c}493,00 \\
573\end{array}$}} & NBR NM 53 \\
\hline Absorção de água (\%) & & & & & \\
\hline Teor de umidade (\%) & \multicolumn{2}{|c|}{1,05} & \multicolumn{2}{|c|}{3,88} & $\begin{array}{c}\text { NBR } 9939 \\
\text { (ABNT, 2011b) }\end{array}$ \\
\hline $\begin{array}{l}\text { Teor de material } \\
\text { pulverulento }(\%)\end{array}$ & \multicolumn{2}{|c|}{2,11} & \multicolumn{2}{|c|}{4,31} & $\begin{array}{c}\text { NBR NM } 46 \\
\text { (ABNT, 2003b) }\end{array}$ \\
\hline
\end{tabular}

\section{Agregados graúdos convencionais}

Utilizou-se como agregados convencionais as britas 0 e 1 (gnaisse), que representaram o grupo de agregados convencionais. As caracterizações foram realizadas por meio dos ensaios de massa específica, absorção de água, teor de umidade e material pulverulento, além da granulometria, com módulo de finura e diâmetro máximo característico, conforme apresentado na Tabela 4 (brita 0 ) e na Tabela 5 (brita 1).

\section{Método}

\section{Amostras para os ensaios no AIMS}

Para os agregados graúdos, foram realizados ensaios de caracterização morfológica de dois tipos de agregados convencionais: a brita 0 (Figura 3a) retida na peneira $4,75 \mathrm{~mm}$ e a brita 1 (Figura 3b) retida na peneira $12,5 \mathrm{~mm}$. As argilas expandidas graúdas utilizadas foram a AE 2215 retida na peneira $12,5 \mathrm{~mm}$ (Figura 3c), constituindo o grupo AE 12,5, e a AE 1506 retida na peneira 9,5mm (Figura 3d), representando o grupo AE 9,5.

A AE utilizada como agregado miúdo foi a AE 0500, retida entre as peneiras 2,36mm (\#8) e $0,075 \mathrm{~mm}$ (\#200), constituindo os grupos de AE 2,36; AE 1,18; AE 0,60; AE 0,30; AE 0,15 e AE 0,075 (Figuras 4a a $4 \mathrm{f}$, respectivamente).

\section{Ensaios do AIMS}

Para realização do ensaio com agregados graúdos, é necessário o mínimo de 50 itens para serem analisados. Dessa forma, foram dispostas 64 amostras individuais da AE 2215 (AE 12,5; Figura 5a) no disco giratório do equipamento. No caso do agregado miúdo (Figura $5 b$ ), para que o contraste entre o grão e o fundo da bandeja fosse possível, houve troca do disco giratório de acordo com a granulometria ensaiada. Os grãos foram dispostos de maneira a ocupar toda a circunferência do disco.

\section{Resultados e discussões}

\section{Angularidade}

Gates et al. (2011) citam que a angularidade do agregado é representada medindo a irregularidade da superfície da partícula a partir do contraste entre a imagem em preto e branco do agregado com a luz de 
fundo da bandeja para as britas 0 e 1 (Figuras 6a e 6b) e para as AE 2215, AE 1506 e AE 0500 (Figuras 7a a 7c). Dessa forma, as varreduras de angularidade produzem as linhas sombreadas ao redor do perfil do agregado.

Tabela 4 - Dados das características do agregado graúdo brita 0

\begin{tabular}{|c|c|c|c|}
\hline $\begin{array}{c}\text { Abertura } \\
\text { das peneiras }(\mathrm{mm})\end{array}$ & $\begin{array}{c}\text { Massa retida } \\
\text { média }(\%)\end{array}$ & $\begin{array}{l}\text { Massa acumulada } \\
\text { média }(\%)\end{array}$ & Norma \\
\hline 19 & $0,00 \%$ & $0,00 \%$ & \\
\hline 12,5 & $0,96 \%$ & $0,96 \%$ & \\
\hline 9,5 & $12,08 \%$ & $13,03 \%$ & \\
\hline 6,3 & $48,02 \%$ & $61,06 \%$ & \\
\hline 4,75 & $25,64 \%$ & $86,70 \%$ & NBR NM 248 \\
\hline 2,36 & $9,67 \%$ & $96,37 \%$ & $(\mathrm{ABN} 1,2003 \mathrm{a})$ \\
\hline Fundo & $3,63 \%$ & $100,00 \%$ & \\
\hline \multicolumn{2}{|l|}{ Módulo de Finura (-) } & 1,96 & \\
\hline \multicolumn{2}{|c|}{ Diâmetro máximo (mm) } & 12,50 & \\
\hline \multirow{3}{*}{\multicolumn{2}{|c|}{$\begin{array}{l}\text { Massa específica real }(\mathrm{kg} / \mathrm{m}) \\
\text { Massa específica seca solta }(\mathrm{kg} / \mathrm{m}) \\
\text { Absorção de água }(\%)\end{array}$}} & 2301 & \\
\hline & & 1879 & $\begin{array}{l}\text { NBK NIMI } 53 \\
\text { (ABNT 2009h) }\end{array}$ \\
\hline & & 0,30 & \\
\hline \multicolumn{2}{|l|}{ Teor de umidade $(\%)$} & 0,19 & $\begin{array}{c}\text { NBR } 9939 \\
\text { (ABNT, 2011b) }\end{array}$ \\
\hline \multicolumn{2}{|c|}{ Teor de material pulverulento $(\%)$} & 0,68 & $\begin{array}{c}\text { NBR NM } 46 \\
(A B N T, 2003 b)\end{array}$ \\
\hline
\end{tabular}

Tabela 5 - Dados das características do agregado graúdo brita 1

\begin{tabular}{c|c|c|c}
\hline $\begin{array}{c}\text { Abertura } \\
\text { das peneiras (mm) }\end{array}$ & $\begin{array}{c}\text { Massa retida } \\
\text { média (\%) }\end{array}$ & $\begin{array}{c}\text { Massa acumulada } \\
\text { média (\%) }\end{array}$ & Norma \\
\hline 19 & $4,87 \%$ & $4,87 \%$ & \\
12,5 & $64,92 \%$ & $69,79 \%$ & \\
9,5 & $21,52 \%$ & $91,31 \%$ & \\
6,3 & $6,69 \%$ & $97,99 \%$ & NBR NM 248 \\
4,75 & $0,92 \%$ & $98,92 \%$ & $($ ABNT, 2003a) \\
2,36 & $0,41 \%$ & $99,33 \%$ & \\
Fundo & $0,67 \%$ & $100,00 \%$ & \\
Módulo de Finura (-) & 2,94 & NBR NM 53 (ABNT, \\
Diâmetro máximo (mm) & 19 & 2009b) \\
\hline Massa específica real (kg/m ) & 1914 & NBR 9939 \\
Massa específica seca solta (kg/m ) & 0,99 & NBR NM 46 \\
Absorção de água (\%) & & 0,39 & (ABNT, 2003b) \\
\hline \multicolumn{2}{l|}{ Teor de umidade (\%) }
\end{tabular}

Figura 3 - Agregados graúdos (a) brita 0; (b) brita 1; (c) AE 2215; e (d) AE 1506
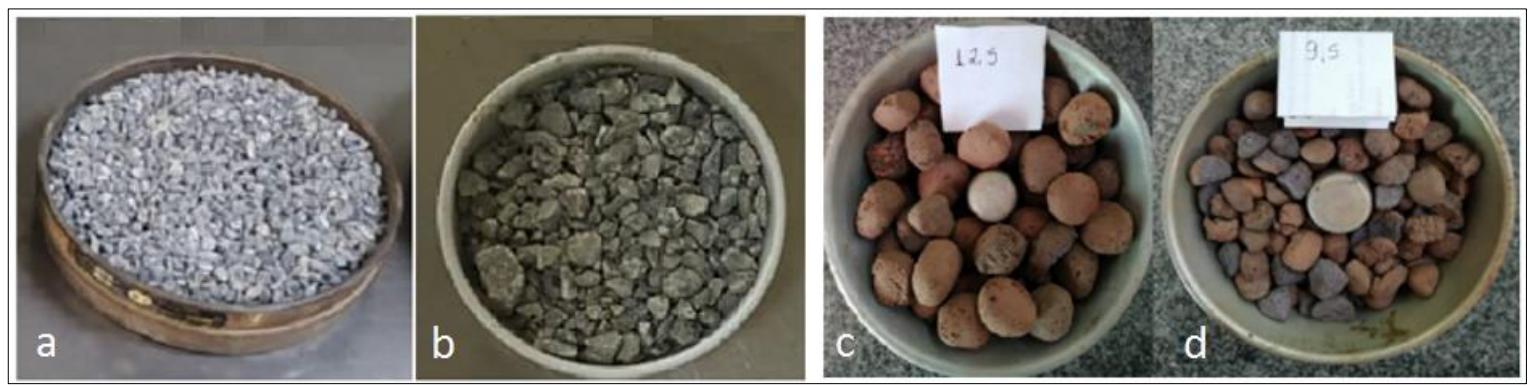
Figura 4 - Frações de peneiramento do agregado miúdo AE 0500: (a) AE 2,36; (b) AE 1,18; (c) AE 0,60; (d) AE 0,30; (e) AE 0,15; e (f) AE 0,075

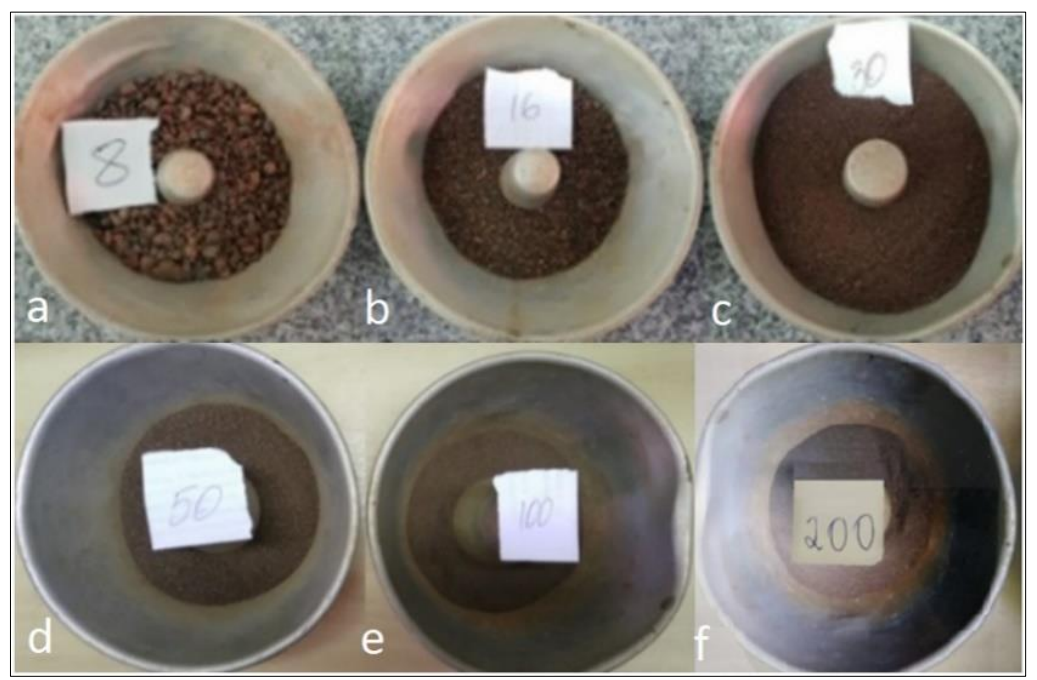

Figura 5 - Disposição dos agregados no interior do AIMS da UFRJ: (a) agregados graúdos [AE 12,5]; e (b) agregados miúdos

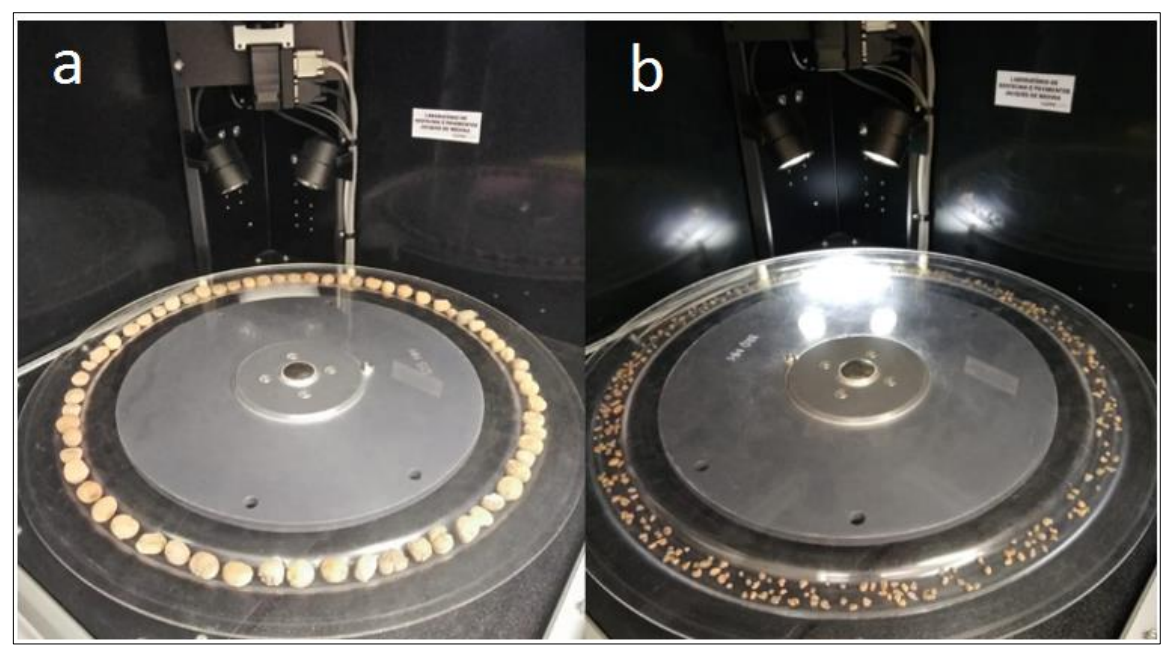

Figura 6 - Imagens fornecidas pelo AIMS para angularidades (a) das britas 0 e (b) das britas 1

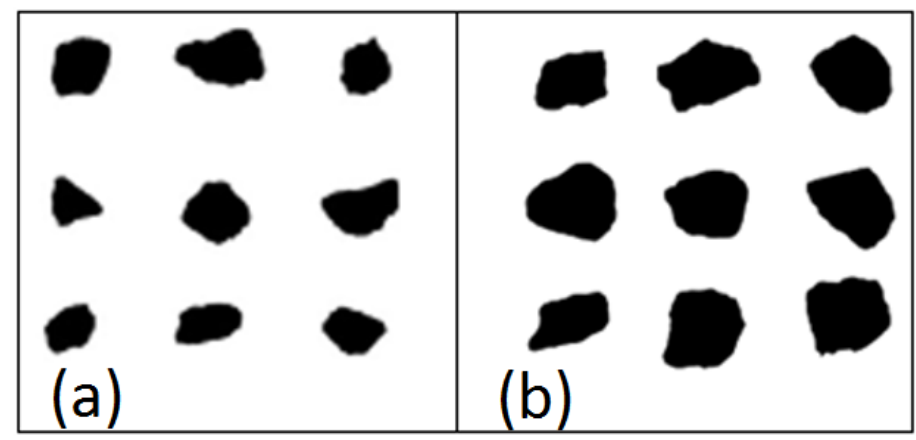


Figura 7 - Imagens fornecidas pelo AIMS para angularidades dos grupos de AE: (a) AE 2215; (b) AE 1506; e (c) AE 0500

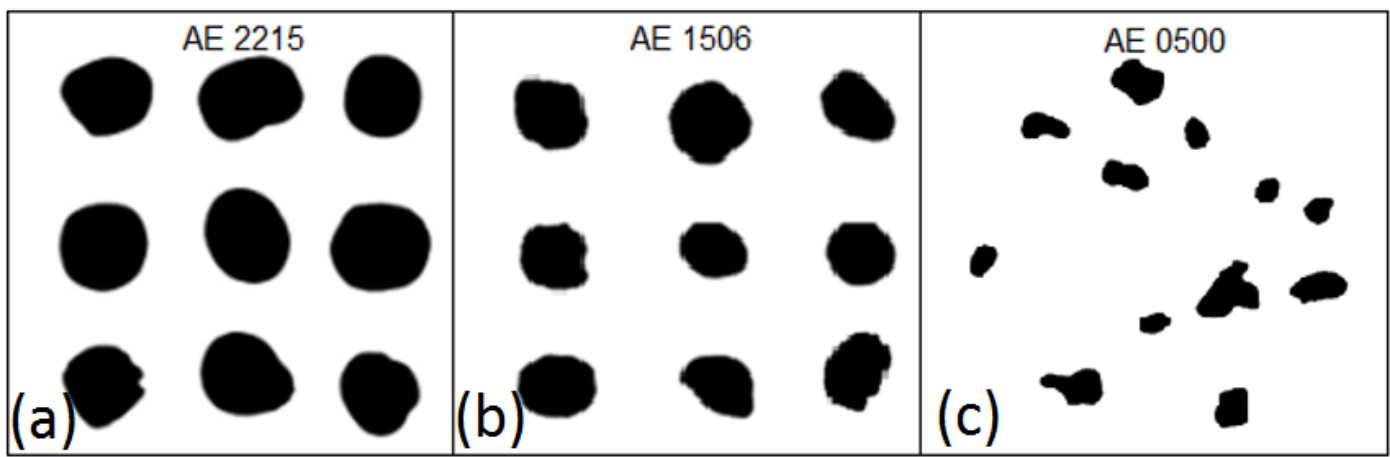

Tabela 6 - Caracterização morfológica quanto à angularidade das britas 0 e 1

\begin{tabular}{c|c|c|c|c|c|c}
\hline \multirow{2}{*}{ Índice de angularidade } & \multicolumn{3}{|c|}{ Brita 0 } & \multicolumn{3}{c}{ Brita 1 } \\
\cline { 2 - 6 } & $\begin{array}{c}\text { Grãos } \\
\text { retidos }\end{array}$ & \% retido & $\begin{array}{c}\text { \% retido } \\
\text { acumulado }\end{array}$ & $\begin{array}{c}\text { Grãos } \\
\text { retidos }\end{array}$ & \% retido & $\begin{array}{c}\text { \% retido } \\
\text { acumulado }\end{array}$ \\
\hline $\begin{array}{c}\text { Arredondada } \\
(\leq 2.100)\end{array}$ & 4 & $8 \%$ & $8 \%$ & 6 & $12 \%$ & $12 \%$ \\
$\begin{array}{c}\text { Subarrendondada } \\
(2.100-3.975) \\
\text { Subangular }\end{array}$ & 37 & $74 \%$ & $82 \%$ & 40 & $80 \%$ & $92 \%$ \\
$\begin{array}{c}(3.975-5.400) \\
\text { Angular } \\
(5.400-10.000)\end{array}$ & 8 & $16 \%$ & $98 \%$ & 4 & $8 \%$ & $100 \%$ \\
\hline Total & 50 & $100 \%$ & - & 50 & $100 \%$ & - \\
\hline
\end{tabular}

Tabela 7 - Caracterização morfológica quanto à angularidade das argilas expandidas

\begin{tabular}{c|c|c|c|c|c|c|c|c|c}
\hline \multirow{2}{*}{$\begin{array}{c}\text { Índice } \\
\text { de angularidade }\end{array}$} & $\begin{array}{c}\text { Grãos } \\
\text { reti- } \\
\text { dos }\end{array}$ & $\begin{array}{c}\text { \% } \\
\text { reti- } \\
\text { do }\end{array}$ & $\begin{array}{c}\text { \% retido } \\
\text { acumula- } \\
\text { do }\end{array}$ & $\begin{array}{c}\text { Grãos } \\
\text { reti- } \\
\text { dos }\end{array}$ & $\begin{array}{c}\% \\
\text { retido }\end{array}$ & $\begin{array}{c}\% \text { retido } \\
\text { acumulado }\end{array}$ & $\begin{array}{c}\text { Grãos } \\
\text { retidos }\end{array}$ & $\begin{array}{c}\% \\
\text { retido }\end{array}$ & $\begin{array}{c}\% \text { retido } \\
\text { acumulado }\end{array}$ \\
\hline $\begin{array}{c}\text { Arredondada } \\
(\leq 2.100)\end{array}$ & 45 & $90 \%$ & $90 \%$ & 32 & $64 \%$ & $64 \%$ & 160 & $18 \%$ & $18 \%$ \\
$\begin{array}{c}\text { Subarrendondada } \\
(2.100-3.975) \\
\text { Subangular }\end{array}$ & 5 & $10 \%$ & $100 \%$ & 17 & $34 \%$ & $98 \%$ & 385 & $43 \%$ & $61 \%$ \\
$\left(\begin{array}{c}3.975-5.400) \\
\text { Angular }\end{array}\right.$ & 0 & $0 \%$ & $100 \%$ & 1 & $2 \%$ & $100 \%$ & 214 & $24 \%$ & $85 \%$ \\
$(5.400-10.000)$ & 0 & $0 \%$ & $100 \%$ & 0 & $0 \%$ & $100 \%$ & 130 & $15 \%$ & $100 \%$ \\
\hline Total & 889 & $100 \%$ & - & 50 & $100 \%$ & - & 50 & $100 \%$ & - \\
\hline
\end{tabular}

Os resultados da caracterização morfológica por grupo de agregados são indicados na Tabelas 6 (britas 0 e 1) e na Tabela 7 (argilas expandidas).

Os valores para as subamostras da AE 0500 são apresentados na Tabela 8.

A representação gráfica da distribuição de angularidade está descrita na Figura 8.

A caracterização morfológica dos agregados graúdos convencionais indica as britas 0 e 1 predominantemente com angularidade subarredondada. Por sua vez, os agregados graúdos de AE brasileira AE 2215 e AE 1506 apresentam angularidade arredondada, e os agregados miúdos de AE, angularidade subarredondada. Observa-se que quanto maior é o diâmetro máximo dos grãos de AE, mais arredondadas são as partículas. 


\section{Esfericidade}

De acordo com Gates et al. (2011), a esfericidade aborda a forma tridimensional das partículas do agregado graúdo. Existe correlação entre o agregado graúdo 3D e a forma 2D; no entanto, a forma 3D é o método mais indicado para analisar a esfericidade, pois considera as três dimensões das partículas em vez de duas dimensões, apresentando resultados mais precisos e consistentes para a análise dessa propriedade.

Os resultados da caracterização morfológica do agregado graúdo quanto à esfericidade são apresentados na Tabela 9 (britas 0 e 1) e Tabela 10 (argilas expandidas).

Na Figura 9 é apresentada a representação gráfica dos agregados analisados.

Tabela 8 - Caracterização morfológica quanto à angularidade das subamostras da AE 0500

\begin{tabular}{c|c|c|c|c|c|c}
\hline Indice de & \multicolumn{7}{|c}{ \% retido acumulado } \\
\cline { 2 - 7 } angularidade & AE 2,36 & AE 1,18 & AE 0,60 & AE 0,30 & AE 0,15 & AE 0,075 \\
\hline $\begin{array}{c}\text { Arredondada } \\
(\leq 2.100)\end{array}$ & $15 \%$ & $17 \%$ & $23 \%$ & $2 \%$ & $17 \%$ & $37 \%$ \\
$\begin{array}{c}\text { Subarrendondada } \\
(2.100-3.975) \\
\text { Subangular }\end{array}$ & $58 \%$ & $68 \%$ & $78 \%$ & $29 \%$ & $50 \%$ & $87 \%$ \\
$(3.975-5.400)$ \\
$\begin{array}{c}\text { Angular } \\
(5.400-10.000)\end{array}$
\end{tabular}

Figura 8 - Distribuição da angularidade dos agregados analisados

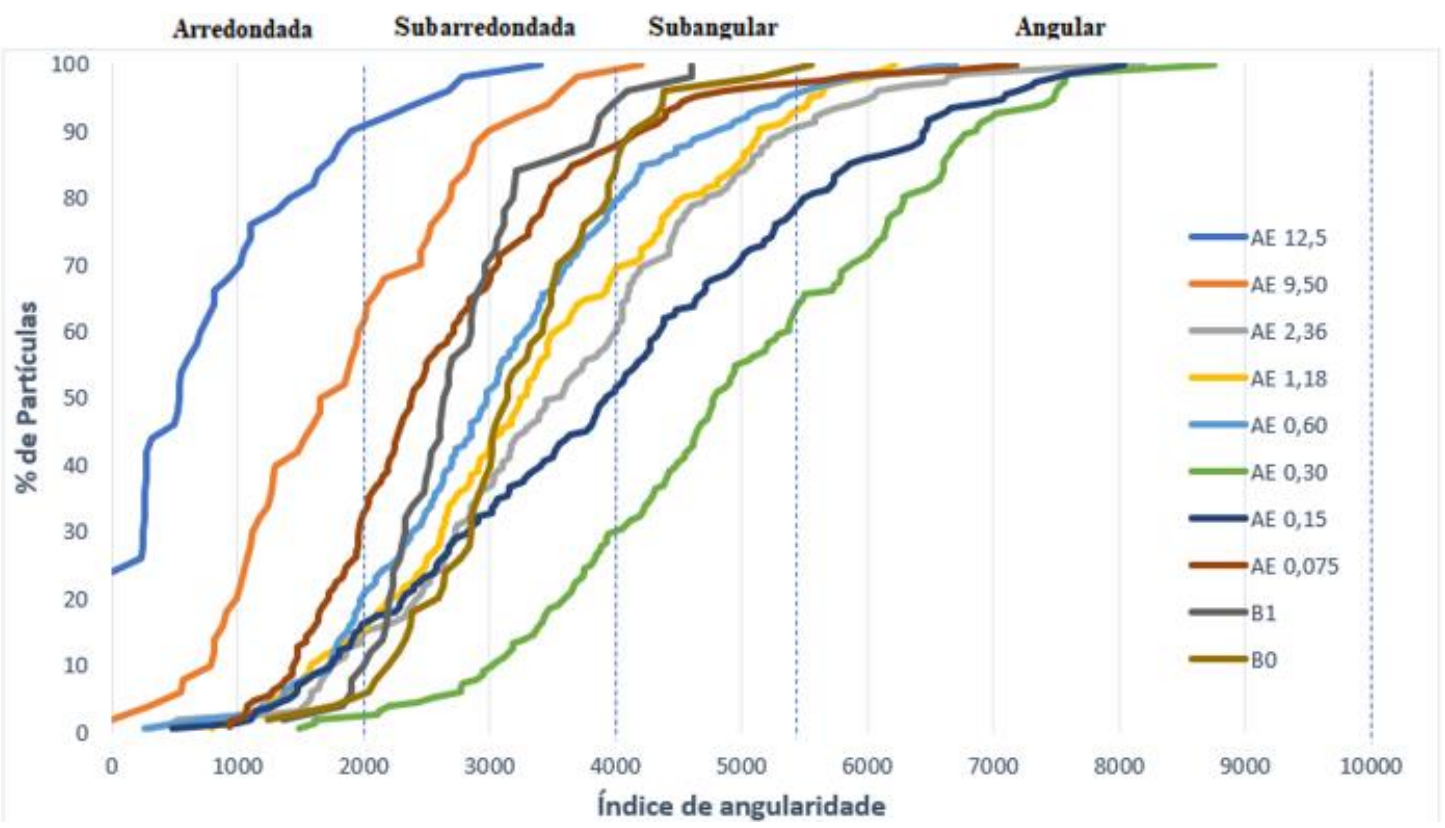

Tabela 9 - Caracterização morfológica quanto à esfericidade das britas 0 e 1

\begin{tabular}{c|c|c|c|c|c|c}
\hline \multirow{2}{*}{ Índice de esfericidade } & \multicolumn{3}{|c|}{ Brita 0 } & \multicolumn{3}{c}{ Brita 1 } \\
\cline { 2 - 7 } & $\begin{array}{c}\text { Grãos } \\
\text { retidos }\end{array}$ & \% retido & $\begin{array}{c}\text { \% retido } \\
\text { acumulado }\end{array}$ & $\begin{array}{c}\text { Grãos } \\
\text { retidos }\end{array}$ & \% retido & $\begin{array}{c}\text { \% retido } \\
\text { acumulado }\end{array}$ \\
\hline Lamelar/alongado $(\leq 0,5)$ & 6 & $12 \%$ & $12 \%$ & 2 & $4 \%$ & $4 \%$ \\
Baixa (0,5-0,6) & 13 & $27 \%$ & $39 \%$ & 14 & $28 \%$ & $32 \%$ \\
Moderada (0,6-0,8) & 25 & $51 \%$ & $90 \%$ & 30 & $60 \%$ & $92 \%$ \\
Alta (0,8-1,0) & 5 & $10 \%$ & $100 \%$ & 4 & $8 \%$ & $100 \%$ \\
Total & 49 & $100 \%$ & - & 50 & $100 \%$ & - \\
\hline
\end{tabular}

222 Nunes, J. J. B. de C.; Teixeira, A. M. A. J.; Saraiva, R. M. D. de C. 
Tabela 10 - Caracterização morfológica quanto à esfericidade das argilas expandidas

\begin{tabular}{c|c|c|c|c|c|c}
\hline \multirow{2}{*}{ Índice de esfericidade } & \multicolumn{3}{|c|}{ AE 1506 (AE 9,5) } & \multicolumn{3}{c}{ AE 2215 (AE 12,5) } \\
\cline { 2 - 7 } & $\begin{array}{c}\text { Grãos } \\
\text { retidos }\end{array}$ & $\begin{array}{c}\text { \% } \\
\text { retido }\end{array}$ & $\begin{array}{c}\text { \% retido } \\
\text { acumulado }\end{array}$ & $\begin{array}{c}\text { Grãos } \\
\text { retidos }\end{array}$ & $\begin{array}{c}\text { \% retido } \\
\text { \% retido } \\
\text { acumulado }\end{array}$ \\
\hline Lamelar/alongado ( $\leq 0,5)$ & 0 & $0 \%$ & $0 \%$ & 0 & $0 \%$ & $0 \%$ \\
Baixa (0,5-0,6) & 1 & $2 \%$ & $2 \%$ & 0 & $0 \%$ & $0 \%$ \\
Moderada (0,6-0,8) & 32 & $64 \%$ & $66 \%$ & 19 & $38 \%$ & $38 \%$ \\
Alta (0,8-1,0) & 17 & $34 \%$ & $100 \%$ & 31 & $62 \%$ & $100 \%$ \\
\hline Total & 50 & $100 \%$ & - & 50 & $100 \%$ & - \\
\hline
\end{tabular}

Figura 9 - Distribuição da esfericidade dos agregados analisados

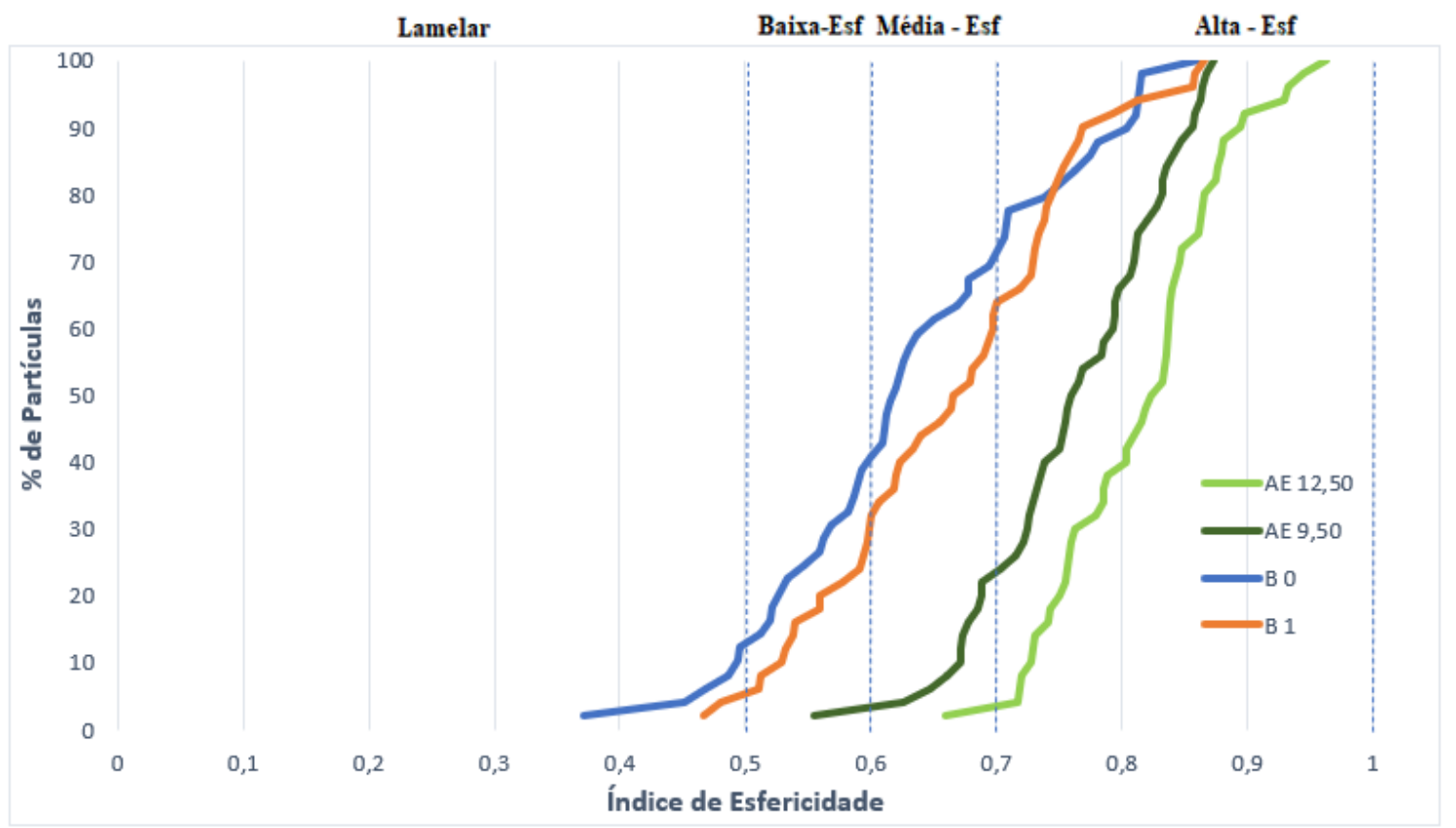

A caracterização morfológica dos agregados graúdos convencionais indica esfericidade moderada para as britas 0 e 1 . No entanto houve diferenciação quanto à esfericidade, para o grupo de agregado graúdo de $\mathrm{AE}$ que apresentou predominantemente alta esfericidade na AE 2215 (AE 12,5) e moderada esfericidade para a AE 1506 (AE 9,5). Observa-se que quanto menor o diâmetro máximo dos grãos de $\mathrm{AE}$, mais lamelares são as partículas.

\section{Textura superficial}

Para a análise da textura superficial, Gates et al. (2011) indicam que pode ser capturada a imagem em escala de cinza da partícula, fornecendo uma caracterização da textura da superfície. A forma tridimensional de cada partícula também é extraída da posição do plano focal na superfície da partícula enquanto o a imagem da textura é capturada.

Os resultados da caracterização morfológica do agregado graúdo quanto à textura superficial são apresentados nas Tabelas 11 (britas 0 e 1) e Tabela 12 (argilas expandidas).

O gráfico da Figura 10 apresenta a distribuição da textura superficial dos agregados analisados.

A caracterização morfológica dos agregados graúdos convencionais indica que a brita 0 apresenta predominantemente textura superficial rugosa, o que corrobora com os estudos de Santana (2017), e que a brita 1 tem textura superficial áspera. No grupo dos agregados leves, ambos os tipos de AE apresentaram predominantemente textura superficial polida. Observa-se que quanto maior é o diâmetro máximo dos grãos de AE, mais polidas são as partículas. 
Tabela 11 - Caracterização morfológica quanto à textura superficial das britas 0 e 1

\begin{tabular}{c|c|c|c|c|c|c}
\hline \multirow{2}{*}{$\begin{array}{c}\text { Índice de textura } \\
\text { superficial }\end{array}$} & \multicolumn{3}{|c|}{ Brita 0 } & \multicolumn{3}{c}{ Brita 1 } \\
\cline { 2 - 7 } & $\begin{array}{c}\text { Grãos } \\
\text { retidos }\end{array}$ & $\begin{array}{c}\text { \% } \\
\text { retido }\end{array}$ & $\begin{array}{c}\text { \% retido } \\
\text { acumulado }\end{array}$ & $\begin{array}{c}\text { Grãos } \\
\text { retidos }\end{array}$ & $\begin{array}{c}\text { \% } \\
\text { retido }\end{array}$ & $\begin{array}{c}\text { \% retido } \\
\text { acumulado }\end{array}$ \\
\hline Polido ( $\leq 200)$ & 7 & $15 \%$ & $15 \%$ & 0 & $0 \%$ & $0 \%$ \\
Liso (200-500) & 11 & $23 \%$ & $38 \%$ & 4 & $8 \%$ & $8 \%$ \\
Rugoso (500-750) & 19 & $40 \%$ & $77 \%$ & 22 & $44 \%$ & $52 \%$ \\
Áspero (750-1000) & 11 & $23 \%$ & $100 \%$ & 24 & $48 \%$ & $100 \%$ \\
\hline Total & 48 & $100 \%$ & - & 50 & $100 \%$ & - \\
\hline
\end{tabular}

Tabela 12 - Caracterização morfológica quanto à textura superficial das argilas expandidas.

\begin{tabular}{c|c|c|c|c|c|c}
\hline \multirow{2}{*}{$\begin{array}{c}\text { Índice de textura } \\
\text { superficial }\end{array}$} & \multicolumn{3}{|c|}{ AE 1506 (AE 9,5) } & \multicolumn{3}{c}{ AE 2215 (AE 12,5) } \\
\cline { 2 - 7 } & $\begin{array}{c}\text { Grãos } \\
\text { retidos }\end{array}$ & $\begin{array}{c}\% \\
\text { retido }\end{array}$ & $\begin{array}{c}\text { \% retido } \\
\text { acumulado }\end{array}$ & $\begin{array}{c}\text { Grãos } \\
\text { retidos }\end{array}$ & $\begin{array}{c}\% \\
\text { retido }\end{array}$ & $\begin{array}{c}\text { \% retido } \\
\text { acumulado }\end{array}$ \\
\hline Polido ( $\leq 200)$ & 24 & $48 \%$ & 0,48 & 30 & $60 \%$ & $60 \%$ \\
Liso (200-500) & 20 & $40 \%$ & 0,88 & 17 & $34 \%$ & $94 \%$ \\
Rugoso (500-750) & 5 & $10 \%$ & 0,98 & 3 & $6 \%$ & $100 \%$ \\
Áspero (750-1000) & 1 & $2 \%$ & 1,00 & 0 & $0 \%$ & $100 \%$ \\
\hline Total & 50 & $100 \%$ & - & 50 & $100 \%$ & - \\
\hline
\end{tabular}

Figura 10 - Distribuição da textura superficial dos agregados analisados

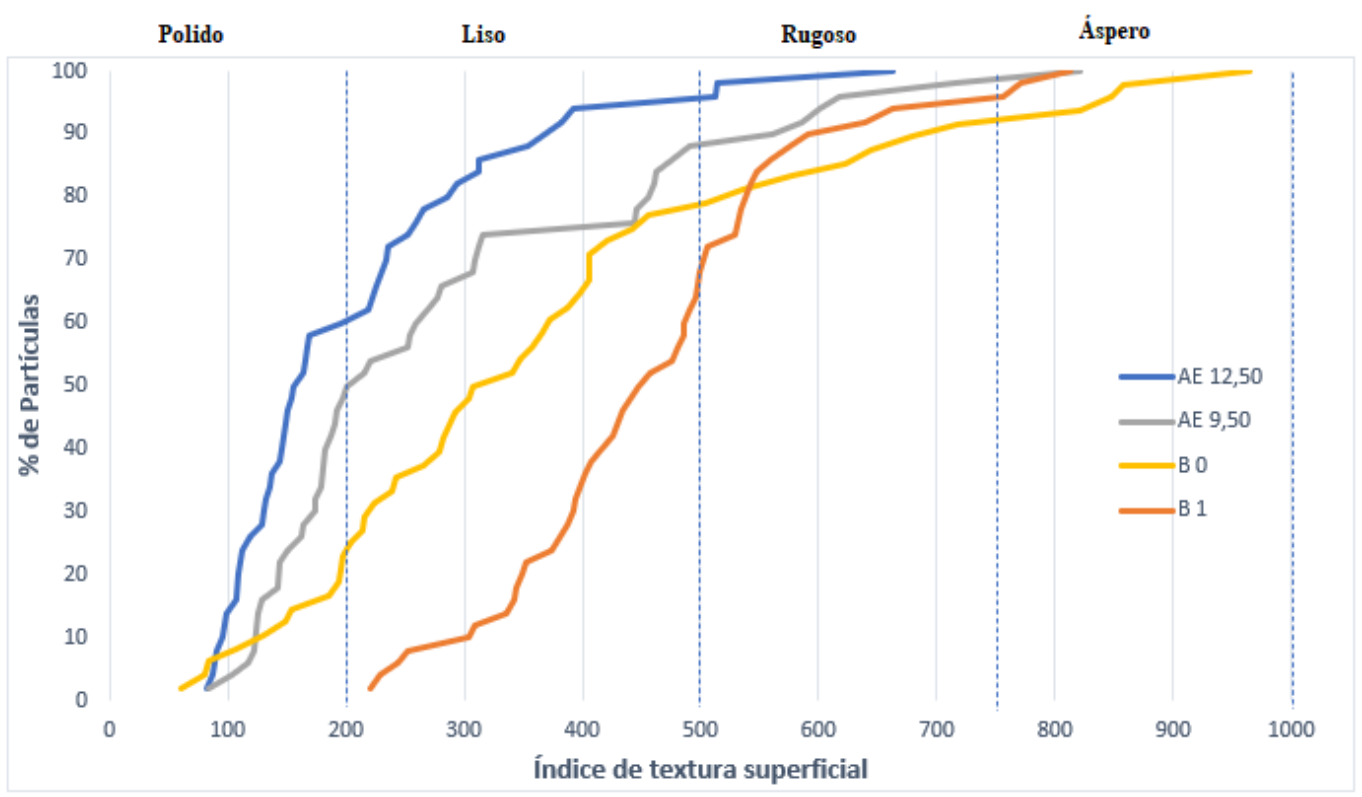

\section{Forma 2D}

O sistema fornece três medições dimensionais para cada partícula de agregado graúdo: largura, comprimento e espessura. Os índices de esfericidade do AIMS são calculados a partir dessas dimensões. Todavia, a informação tridimensional não está disponível para os agregados miúdos. Por isso, para sua caracterização, o AIMS utiliza a forma 2D para determinar o índice de forma.

Os resultados da caracterização morfológica do agregado miúdo quanto ao formato 2D são apresentados na Tabela 13 para o grupo da AE 0500 e na Tabela 14 para as subamostras da AE 0500.

No gráfico da Figura 11 observa-se a distribuição do formato 2D do agregado miúdo de AE.

Os agregados miúdos de $\mathrm{AE}$ foram classificados, quanto ao formato $2 \mathrm{D}$, predominantemente com formato circular para os grupos de AE 2,36/AE 1,18/AE 0,60. Por sua vez, os grupos de AE 0,30/AE 0,15/AE 0,075 foram classificados predominantemente com formato semialongado. 
Tabela 13 - Caracterização morfológica quanto ao formato da AE 0500

\begin{tabular}{c|c|c|c}
\hline Índice de forma & Grãos retidos & \% retido & \% retido acumulado \\
\hline Circular $(\leq 6,5)$ & 265 & $30 \%$ & $30 \%$ \\
Semicircular $(6,5-8)$ & 234 & $26 \%$ & $56 \%$ \\
Semialongado (8-10,5) & 290 & $32 \%$ & $89 \%$ \\
Alongado (10,5-20) & 99 & $11 \%$ & $100 \%$ \\
\hline Total & 888 & $100 \%$ & - \\
\hline
\end{tabular}

Tabela 14 - Caracterização morfológica quanto ao formato 2D das subamostras da AE 0500

\begin{tabular}{c|c|c|c|c|c|c}
\hline \multirow{2}{*}{ Índice de forma } & \multicolumn{7}{|c}{ \% retido acumulado } \\
\cline { 2 - 7 } & AE 2,36 & AE 1,18 & AE 0,60 & AE 0,30 & AE 0,15 & AE 0,075 \\
\hline Circular ( $\leq 6,5)$ & $40 \%$ & $42 \%$ & $48 \%$ & $9 \%$ & $23 \%$ & $14 \%$ \\
Semicircular (6,5-8) & $69 \%$ & $69 \%$ & $79 \%$ & $33 \%$ & $44 \%$ & $39 \%$ \\
Semialongado (8-10,5) & $95 \%$ & $94 \%$ & $96 \%$ & $81 \%$ & $84 \%$ & $82 \%$ \\
Alongado (10,5-20) & $100 \%$ & $100 \%$ & $100 \%$ & $100 \%$ & $100 \%$ & $100 \%$ \\
\hline
\end{tabular}

Figura 11 - Distribuição do formato 2D do agregado miúdo de AE

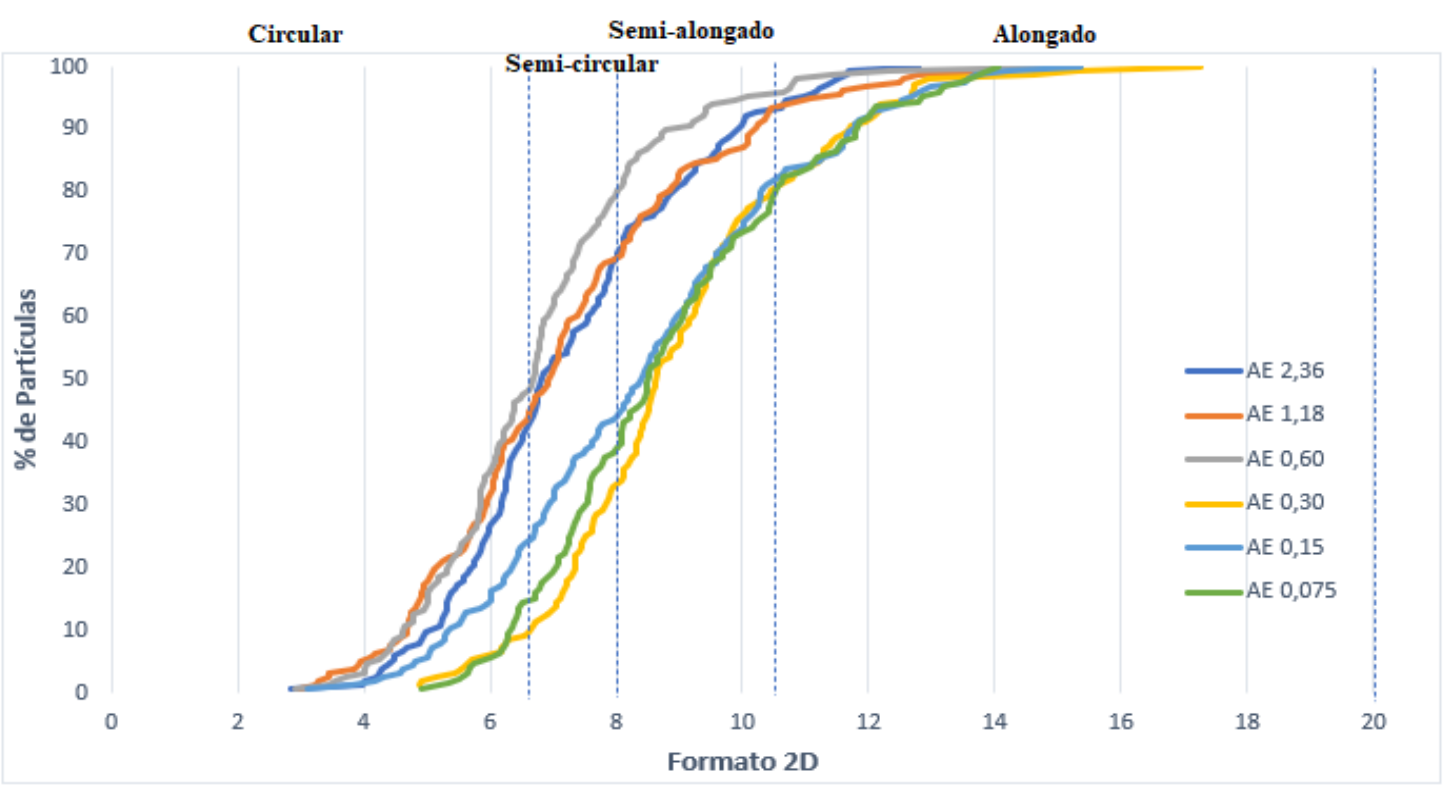

\section{Conclusão}

A caracterização de agregados convencionais ou leves por meio do AIMS se mostrou eficiente devido à rapidez com que os parâmetros são coletados e por obter dados condizentes com a literatura pesquisada.

Observa-se que quanto maior é o diâmetro máximo dos grãos de AE, mais arredondadas, esféricas e polidas são as partículas quanto a aspectos de angularidade, esfericidade e textura superficial, respectivamente. A AE 0500 apresenta predominância de formato semialongado, o que é esperado devido ao comportamento mais uniforme de suas subamostras, com maior percentual retido acumulado na faixa de 8 e 10,5.

Os resultados apresentados neste trabalho corroboram com Rossignolo (2009), em que se observa que o processo de fabricação da $\mathrm{AE}$, que ocorre em fornos rotativos, aumenta a característica de arredondamento das partículas e produz uma casca vitrificada, resistente e de baixa permeabilidade, o que explica a conformação polida dos grãos analisados.

Por outro lado, uma análise mais atenta à textura superficial das argilas expandidas esclarece aspectos relativos à menor aderência se comparada ao agregado convencional, além do comportamento distinto na interação entre o agregado e a matriz de cimento na zona de transição, devido a aspectos de rugosidade e absorção de água. Esse fato também foi observado por Zhang e Gjorv (1991) e apontado nos estudos de 
Santana (2017) quanto à utilização do AIMS para fornecimento das características sobre índice de forma, angularidade, textura e esfericidade da brita 0 .

\section{Referências}

AMERICAN CONCRETE INSTITUTE. ACI 213R-14: Guide for structural lightweight aggregate concrete. Farmington Hills, 2014.

ASSOCIAÇÃO BRASILEIRA DE NORMAS TÉCNICAS. NBR 7809: agregado graúdo: determinação do índice de forma pelo método do paquímetro: método de ensaio. Rio de Janeiro, 2008.

ASSOCIAÇÃO BRASILEIRA DE NORMAS TÉCNICAS. NBR 9775: agregado miúdo: determinação do teor de umidade superficial por meio do frasco de Chapman: método de ensaio. Rio de Janeiro, $2011 \mathrm{a}$.

ASSOCIAÇÃO BRASILEIRA DE NORMAS TÉCNICAS. NBR 9939: agregado graúdo: determinação do teor de umidade total: mMétodo de ensaio. Rio de Janeiro, $2011 \mathrm{~b}$.

ASSOCIAÇÃO BRASILEIRA DE NORMAS TÉCNICAS. NBR NM 248: agregados: determinação da composição granulométrica. Rio de Janeiro, 2003a.

ASSOCIAÇÃO BRASILEIRA DE NORMAS TÉCNICAS. NBR NM 46: agregados: determinação do material fino que passa na peneira 75 micrometros por lavagem. Rio de Janeiro, $2003 \mathrm{~b}$.

ASSOCIAÇÃO BRASILEIRA DE NORMAS TÉCNICAS. NBR NM 52: agregado miúdo: determinação de massa específica e massa específica aparente. Rio de Janeiro, 2009a.

ASSOCIAÇÃO BRASILEIRA DE NORMAS TÉCNICAS. NBR NM 53: agregado graúdo: determinação de massa específica, massa específica aparente e absorção de água. Rio de Janeiro, 2009b.

AZEVEDO, A. C. L. de. Vigas pultrudadas preenchidas com concreto para dormentes ferroviários. Rio de Janeiro: Instituto Militar de Engenharia, 2017.

BESSA, I. S. Avaliação do processamento digital de imagens como ferramenta para caracterização de agregados e misturas asfálticas. Dissertação (Mestrado em Engenharia de Transportes) - Programa de PósGraduação em Engenharia de Transportes, Universidade Federal do Ceará, Fortaleza, 2012.

CASTELO BRANCO, V. T. F. et al. Caracterização de forma, angularidade e textura de agregado de brita granítica e escórias de aciaria usando o Aggregate Imaging System (AIMS). In: CONGRESSO DE PESQUISA E ENSINO EM TRANSPORTES, 20., Brasília, 2006. Anais [...] Brasília: ANPET, 2006.

CINEXPAN. Tipo de argila expandida. 2000. Disponível em: https://www.cinexpan.com.br. Acesso em: 15 abr. 2020.

COMITE EURO-INTERNACIONAL DU BETON E FEDERATION INTERNATIONALE DE LA PRECONTRAINTE. Ligthweight aggregate concrete: manual of design and tecnology. New York: Construction Press, 1977.

GOPI, R. et al. Light expanded clay aggregate and fly ash aggregate as self-curing agents in self-compacting concrete. Asian Journal of Civil Engineering, v. 16, n. 7, p. 1025-1035, 2015.

GATES, L. et al. US Department of Transportation Federal Highway Administration. Aggregate Image Measurement System 2 (AIMS2). Final Report. Federal Highway Administration Under the Highways for LIFE Program, FHWA-HIF-11-030, 2011.

MAYCÁ, J.; RECENA, F. A. P.; CREMONINI, R. A. Contribuição ao estudo da argila expandida nacional como alternativa de agregado graúdo para concretos leves estruturais. Curso de especialização (Engenharia Civil) - Universidade Federal do Rio Grande do Sul, Porto Alegre, 2008.

MORAVIA, W. G. et al. Caracterização microestrutural de argila expandida para aplicação como agregado em concreto estrutural leve. In: CONGRESSO BRASILEIRO DE CERÂMICA, 48., Curitiba, 2004. Anais [...] Curitiba, 2004.

MORAVIA, W. G.; GUMIERI, A. G.; VASCONCELOS, W. L. Fator de eficiência e módulo de elasticidade do concreto leve com argila expandida. IBRACON - Structures and Materials Journal, v. 3, n. $2,2010$.

ROSSIGNOLO, J. A. Concreto leve estrutural: produção, propriedades, microestrutura e aplicações. São Paulo: Pini, 2009.

226 Nunes, J. J. B. de C.; Teixeira, A. M. A. J.; Saraiva, R. M. D. de C. 
SANTANA, C. S. A. Propriedades de concreto projetado com fibras de poliolefina para túneis. Rio de Janeiro, 2017. Dissertação (Mestrado em Engenharia de Transportes) - Instituto Militar de Engenharia, Rio de Janeiro, 2017.

ZHANG, M. H.; GJ $\phi R V$, O. E. Mechanical properties of high-strength lightweight concrete. ACI Materials Journal, v. 88, n. 3, p. 240-247, 1991.

Júlio Jorge Braga de Carvalho Nunes

Instituto Militar de Engenharia | Praça General Tibúrcio, 80, Praia Vermelha | Rio de Janeiro - RJ - Brasil | CEP CEP 22290-270 | Tel.: (21) 2546-7028 | E-mail: julio.nunes@ime.eb.br

Ana Maria Abreu Jorge Teixeira

Instituto Militar de Engenharia | E-mail: anam@ime.eb.br

Rebeca Montenegro Dias de Carvalho Saraiva

Instituto Militar de Engenharia | Tel.: (21) 2546-7021 | E-mail: rebeca@ime.eb.br

Ambiente Construído

Revista da Associação Nacional de Tecnologia do Ambiente Construído

Av. Osvaldo Aranha, $99-3^{\circ}$ andar, Centro

Porto Alegre - RS - Brasil

CEP $90035-190$

Telefone: +55 (51) 3308-4084

www.seer.ufrgs.br/ambienteconstruido

www.scielo.br/ac

E-mail: ambienteconstruido@ufrgs.br 